\title{
QUALIDADE DE VIDA E USO DO TERRITÓRIO POR IMIGRANTES HAITIANOS NO MUNICÍPIO DE ANDRADAS (MG)
}

João Vitor de Freitas ${ }^{1}$

Gil Carlos Silveira Porto²

RESUMO: O presente texto discorre sobre a vinda de migrantes haitianos para o Brasil, sobre como a dinâmica espacial do local onde se fixaram aqui no Brasil se alterou e, consequentemente, sobre a maneira como o território é ocupado. No município de Andradas (MG), haitianos e haitianas vêm se concentrando e trazendo suas famílias desde o terremoto que devastou o Haiti em 2010. O embasamento teórico se deu pela leitura não só de autores que discutem o tema da migração haitiana, mas também autores que abordam a questão do uso do território. O desenvolvimento da pesquisa que resultou neste artigo se deu por meio de revisão da literatura, consulta aos sites do IBGE e da Prefeitura Municipal de Andradas, bem como conversa informal com haitianos que residem na cidade. Ao final, compreende-se que as práticas cotidianas desse grupo migratório modificam o território pelo seu uso, seja nos espaços laborais ou na participação de cultos em igrejas por eles criadas.

PALAVRAS-CHAVE: Andradas; haitianos; território; qualidade de vida; moradia.

\section{QUALITY OF LIFE AND USE OF TERRITORY BY HAITIANS IMMIGRANTS IN THE MUNICIPALITY OF ANDRADAS (MG)}

\begin{abstract}
This text discusses the arrival of Haitian migrants to Brazil, how the spatial dynamics of the place where they settled here in Brazil changed, and consequently the way in which the territory is occupied. In the municipality of Andradas (MG), Haitians and Haitians have been concentrating and bringing their families since the earthquake that devastated Haiti in 2010. The theoretical basis was given by the reading not only of authors who discuss the theme of Haitian migration but also of authors that approach the issue of land use. The development of the research that resulted in this article took place through a literature review, consultation on the websites of the IBGE and the Municipal Goverment, as well as informal conversations with Haitians who live in the city. In the end, it is understood that the daily practices of this migratory group modify the

\footnotetext{
1 Discente do curso de Geografia Bacharelado da Unifal-MG. Bolsista PIBIC/CNPQ. E-mail: freitasgeo18@gmail.com

2 Docente do curso de Geografia e do Programa de Pós-graduação em Geografia da Unifal-MG. Email: gil.porto@unifal-mg.edu.br
} 
territory by its use, either in their work spaces or in the participation in cults in churches created by them.

KEYWORDS: Andradas; haitians; territory; quality of life; housing.

\section{CALIDAD DE VIDA Y USO DEL TERRITORIO POR INMIGRANTES HAITIANOS EN EL MUNICIPIO DE ANDRADAS (MG)}

RESUMEN: Este texto analiza la llegada de migrantes haitianos a Brasil, la manera cómo cambió la dinámica espacial del lugar donde se asentaron aquí en Brasil y, en consecuencia, la forma en que se ocupa el territorio. En el municipio de Andradas (MG), haitianos y haitianos se han venido concentrando y trayendo a sus familias desde el terremoto que asoló Haití en 2010. La base teórica estuvo dada por la lectura no solo de autores que discuten el tema de la migración haitiana, sino también de autores que discuten el tema del uso del suelo. El desarrollo de la investigación que dio lugar a este artículo se llevó a cabo a través de una revisión de la literatura, la consulta en los sitios web del IBGE y el Ayuntamiento de Andradas, así como conversaciones informales con haitianos que viven en la ciudad. Al final, se entiende que las prácticas cotidianas de este grupo migratorio modifican el territorio por su uso, ya sea en sus espacios de trabajo o en la participación en cultos en iglesias creadas por ellos.

Palabras Clave: Andradas; haitianos; territorio; calidad de vida; alojamento.

INTRODUÇÃO

Em 2010, um terremoto atingiu a cidade de Puerto Príncipe, capital do Haiti. Esse evento pode ser considerado como umas das maiores catástrofes naturais do século, causando a morte de cerca de duzentas mil pessoas e deixando milhares de pessoas sem moradia. Também em função desse evento, muitos haitianos, influenciados pela Missão de Paz feita pela ONU em parceria com o Brasil e que teve seu fim em 2010, deixaram seu país de origem em busca de melhorias de suas condições de vida em muitos países, entre eles o Brasil. Cabe ressaltar que a história da formação socioespacial haitiana é marcada pela emigração, movimento que foi intensificado pelo terremoto.

Um dos grandes pilares da geografia como ciência é o território. Compreender o funcionamento do território, saber quem o ocupa e como ele se 
altera permite uma visão mais clara e abrangente do espaço geográfico, entendido por nós como uma totalidade em movimento. Dessa forma, diferentes fatores e grupos humanos podem alterar a maneira com que o território é formado, incluindo o seu uso e as pessoas por quem ele é utilizado.

A principal intenção deste escrito foi compreender como os imigrantes haitianos que habitam em Andradas (MG) usam o território desse município. Para isso, muitos fatores foram tratados como requisitos para compreender essa dinâmica. A principal variável tratada foi a qualidade de vida, pois a forma como esse grupo demográfico acessa a saúde, a educação e a moradia revelam as características do uso do território municipal.

Outro importante aspecto deste trabalho consistiu em compreender que esse tipo de análise pode auxiliar no planejamento e na melhoria das condições de vida desses haitianos, pois revela suas necessidades. Desse modo, além de lançar um olhar crítico sobre o fenômeno migratório, enxergar a maneira como aquele território está sendo utilizado e vislumbrar políticas de governo para esse estrato populacional também é relevante.

A metodologia utilizada para esta pesquisa foi dividida em quatro etapas. A primeira consistiu na revisão da literatura, a segunda na realização de conversa informal com um imigrante que reside em Andradas (MG), a terceira foi através da análise de experiências de vidas narradas por imigrantes, em painéis como o II Colóquio Sobre Migração e Espaço Geográfico (2020), e a quarta etapa consistiu na consulta do material disponibilizado pela Prefeitura do município de Andradas (MG). Essas etapas possibilitaram a compreensão dos conceitos geográficos abordados, como, por exemplo, o de território, e permitiram entender melhor as condições migratórias desses haitianos.

Ainda no concernente à metodologia desenvolvida, é importante ressaltar que a pesquisa, cujos resultados são aqui apresentados, foi realizada a partir de uma abordagem crítica. Mediante a análise dos estudos feitos por autores como 
Paulo Netto (2011), Santos (1988, 2000) e Souza (2019), optou-se por conceitos que pudessem auxiliar na interpretação do fenômeno abordado pela Geografia.

\section{ASPECTOS DA DINÂMICA POPULACIONAL}

Como se observa na Figura 1, o município de Andradas se localiza na microrregião de Poços de Caldas, que integra a mesorregião Sul/Sudoeste de Minas, constituindo assim um dos 155 municípios localizados neste recorte regional.

De acordo com os dados demográficos fornecidos pelo IBGE (2010), Andradas possui 28.026 habitantes residentes na parte urbana e 9.244 na área rural. Ainda de acordo com Censo de 2010, observou-se que a população municipal que se considera negra é composta por 1.064 habitantes, enquanto a população branca perfaz 29.611 habitantes.

Figura 1 - Localização Geográfica do município de Andradas (MG) 


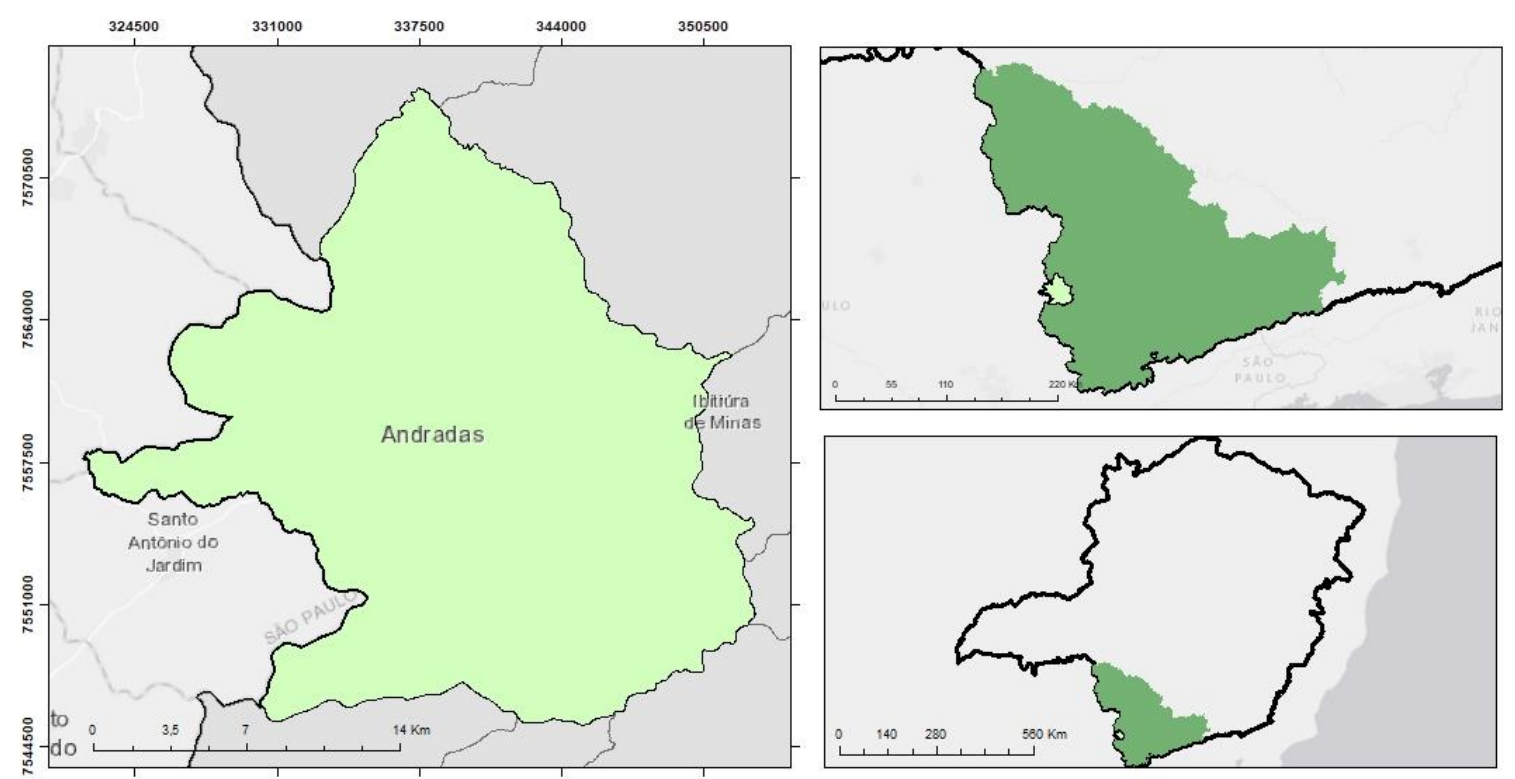

Localização de Andradas (MG)

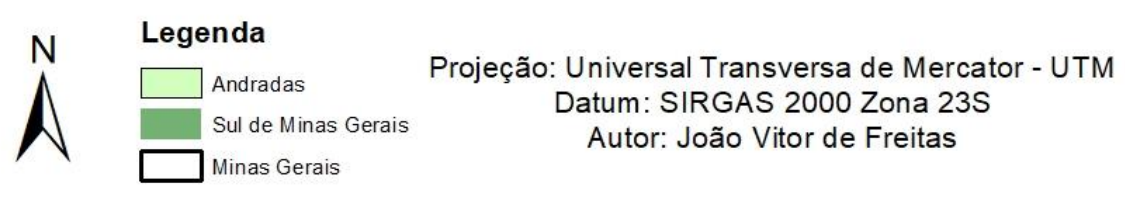

Fonte: IBGE, 2020.

É de grande necessidade a análise desses dados étnico-raciais, pois eles permitem a compreensão de como é a população de Andradas. A diferença de sua localização geográfica e sua diferença étnico-racial podem estar ligadas à maneira como será feito o uso do território, pois ela condiciona as questões sociais em que esses imigrantes haitianos estarão envolvidos, como, por exemplo, o modo com que usam o território de Andradas.

Dessa forma, pessoas que vivem em áreas rurais e pessoas que vivem em áreas urbanas possuem diferentes questões do dia a dia, alterando assim a dinâmica social desses indivíduos. Essa dinâmica muda a maneira com que se usa o território. Quanto à questão do racismo, um ambiente no qual as pessoas sofrem esse tipo de preconceito pode condicionar a reclusão delas próprias e lhes infundir o sentimento de não pertencimento àquele local, o que pode limitar dessa forma o uso do território. 
Já em relação à estrutura demográfica, a população do município de Andradas se caracteriza por uma pirâmide etária predominantemente jovem, com seu maior número de habitantes pertencentes ao grupo com idade entre 20 a 29 anos, como se observa na Figura 2.

Figura 2 - Distribuição da população por sexo, segundo os grupos de idade Andradas (MG).

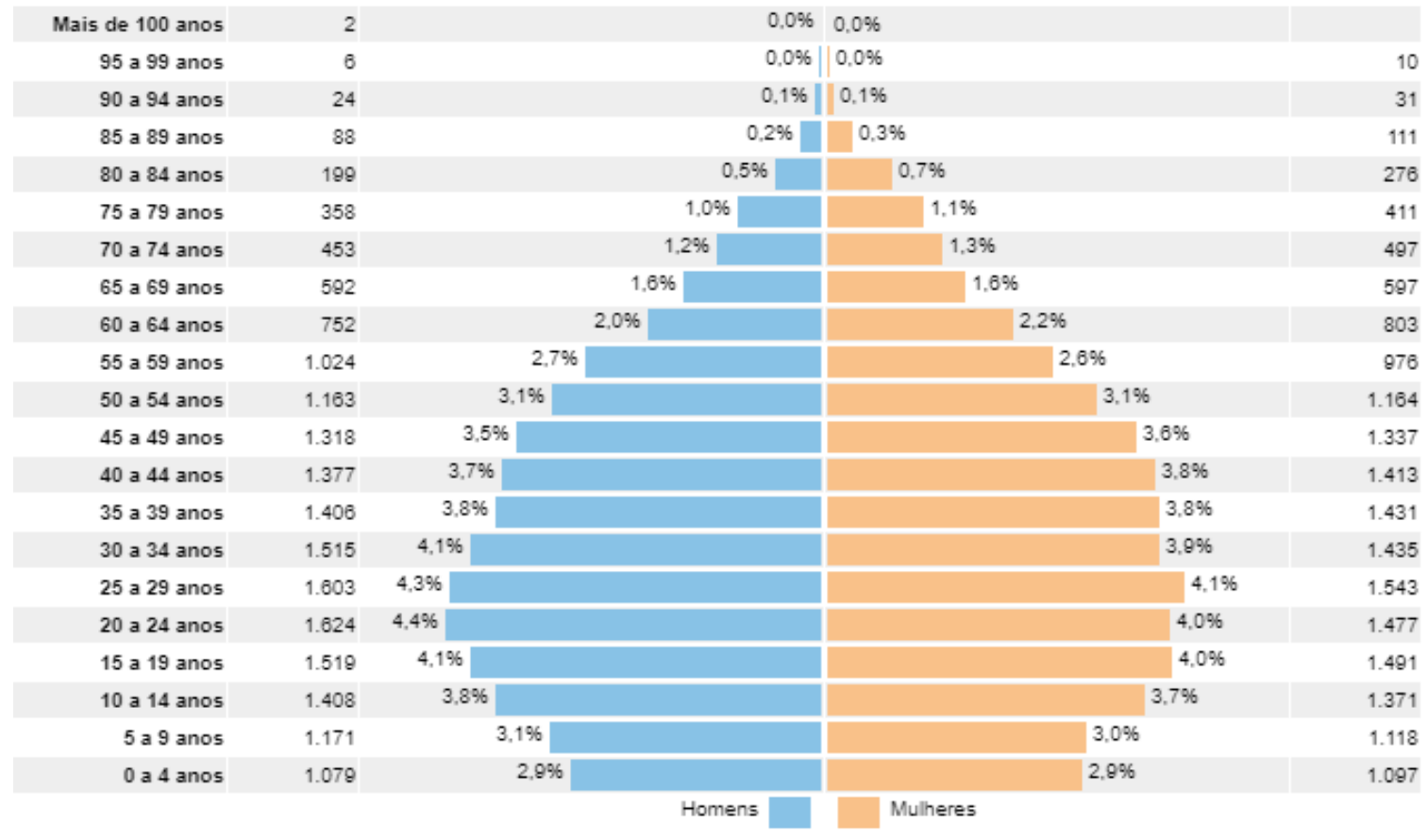

Fonte: IBGE (2010)

Ademais, segundo informação fornecida pelo Portal da Prefeitura Municipal de Andradas, o município conta com 37.270 habitantes, sendo que a quantidade de homens e de mulheres é bem próxima (homens com uma pequena quantidade a mais que as mulheres). Também é mostrado que, do total de habitantes, 35.442 possuem religiões, distribuídos entre católicos, evangélicos e espíritas (sendo que o catolicismo predomina no município).

Em relação à presença estrangeira, ainda de acordo com o Censo (IBGE, 2010), existiam no município 27 imigrantes de origem estrangeira (não apenas haitianos); já uma reportagem feita pelo Portal de Andradas em 2015 mostrava 
que o município contava com 45 imigrantes haitianos, número que aumentou consideravelmente, pois de acordo com Louis Delhomme Desinord, 39 anos (2020), haitiano que vive em Andradas e que participou da mesa-redonda do II Colóquio sobre Migrações e Espaço Geográfico, tem ocorrido reunião familiar à medida que os anos passam, impulsionando o aumento do número de haitianos no município (porém, ainda não é possível afirmar exatamente quantos imigrantes haitianos ali residem); O próprio Louis chegou sem a esposa e os filhos ao Brasil, mas hoje eles já se encontram no Sul de Minas.

Ainda de acordo com o Portal de Andradas, o Índice de Desenvolvimento Humano (IDH) do município em 2010 era de 0,734, considerado próximo de alto $(0,800$ - 1). Também o índice de Gini (medidor de desigualdade de renda domiciliar por indivíduo), era de 0,44 (sendo o máximo 1). Outro dado importante refere-se à pobreza. Em 2010 o índice de pobreza no município era de 13,64\% (considerado baixo).

Um bom parâmetro para compreendermos esse dado é analisarmos o IDH de São Paulo, que é de 0,805 (2010). A proximidade de valores com a cidade de São Paulo nos permite afirmar que o IDH de Andradas é bom. Quanto ao índice de pobreza, São Paulo apresenta $26,60 \%$, quase o dobro do valor apresentado em Andradas-MG.

De maneira geral, esses dados mostram que naquele ano a desigualdade era baixa no município. No entanto, há que se investigar qual foi o impacto da chegada dos haitianos na sociedade local como um todo, pois pode ter ocorrido um aumento do número de trabalhadores, da renda, relacionada com o envio de remessas, pois normalmente os imigrantes enviavam dinheiro para suas famílias que ficaram em seus países (SILVA; CORSINI, 2019).

É de grande significância ressaltar que, com a chegada desses haitianos, principalmente após o terremoto de 2010 e ante a falta de um Censo elaborado no ano de 2020, não se pode afirmar que a chegada dos imigrantes haitianos 
contribuiu para o aumento da pobreza no município, porém as condições de vida e de trabalho que muitos deles enfrentam contradizem os dados de grande desenvolvimento apontados para o município em 2010.

De modo geral, a importância de compreender os aspectos da população liga-se à necessidade de elucidar, primeiramente, como é formado o município de Andradas, para assim entender como os estrangeiros modificam o território do município. Dependendo de como esses haitianos se espalham e se encaixam em Andradas, a forma como utilizam o território é diferente.

\section{MORADIA E EQUIPAMENTOS PÚBLICOS}

A questão da saúde do imigrante haitiano vai além do simples acesso a saneamento básico, pois envolve também a localização geográfica de sua moradia no município e o modo como ali são recebidos. O município de Andradas (MG) possui 83 bairros na área urbana, com presença de noventa bairros rurais, divididos em catorze setores e dois distritos. Os distritos são os de Campestrinho e Gramínea (SECRETARIA DE PLANEJAMENTO URBANO DE ANDRADAS, 2020).

Compreender a questão dos bens materiais também permite entender como é realmente a condição dos habitantes do município (e, consequentemente, dos haitianos). Dessa forma, o uso do território por esse segmento demográfico é um reflexo de suas condições de vida, incluindo seus bens materiais. A Tabela 1 esquematiza o número de habitantes municipais que possuem acesso a tais bens: 


\begin{tabular}{lcc}
$\begin{array}{l}\text { Tabela 1: } \\
\text { 2010. }\end{array}$ & Relação de bens materiais por habitantes em Andradas (MG), \\
\hline & 9.236 & RURAL \\
\hline Geladeira & 5.056 & 2.773 \\
$\begin{array}{l}\text { Máquina de Lavar } \\
\text { Roupa }\end{array}$ & 523 \\
$\begin{array}{l}\text { Automóvel (uso } \\
\text { particular) }\end{array}$ & 1.914 \\
Microcomputador & 4.139 & 459 \\
Telefone Celular & 7.925 & 2.489 \\
\hline Fonte: IBGE, 2010. & & \\
\hline
\end{tabular}

Devido à impossibilidade de realização de trabalho de campo por conta da pandemia da Covid-19, torna-se difícil a análise em profundidade da qualidade de vida dos haitianos que vivem em Andradas. O surgimento da Covid-19 ocorreu no ano de 2019 na China, e ao longo de 2020 a moléstia se espalhou pelo mundo, classificando-se como uma pandemia, fazendo com que medidas de saúde como o isolamento fossem tomadas para evitar os riscos à exposição ao vírus da Covid19. Dessa forma, por respeito aos andradenses, aos imigrantes haitianos e às famílias dos pesquisadores não foram feitos trabalhos de campo.

Foi informado, por meio de conversas remotas com a Secretaria de Educação de Andradas (2020) e mediante informações obtidas em conversa remota com Louis, que os haitianos presentes no local habitam a área urbana (visto não se identificar nenhuma matrícula de haitianos nas escolas rurais), trabalham em sua maioria nas indústrias e na fábrica de rosquinhas, sendo que a maioria dos que trabalham na fábrica de rosquinhas é formada por mulheres que trabalham na produção.

De acordo com matéria do G1 de 15 de maio de 2014, onde são feitas entrevistas com imigrantes haitianos do município de Andradas acerca de 
questões de qualidade de vida e trabalho, os imigrantes afirmam que trabalham em uma empresa que fabrica louças sanitárias. Isso indica como a questão do trabalho também é responsável por moldar o uso do território pelos haitianos, pois revela como serão as relações com os andradenses. Além disso, também mostra como são as condições de trabalho.

O Plano Diretor do município de Andradas pretende adequar o município a alguns quesitos, na intenção de melhorar a qualidade de vida dos habitantes. Alguns dos principais intuitos inscritos no Plano Diretor são: elevar a qualidade de vida urbana, reduzir a desigualdade entre as regiões e democratizar o acesso à terra, entre outros objetivos (ANDRADAS, 2017, Art. 9); porém não se aborda a questão dos refugiados ou dos imigrantes, como no caso dos haitianos.

$\mathrm{O}$ acesso à moradia e à terra em si contribui para esta pesquisa por estarem elas diretamente ligadas à questão do território e, consequentemente, ao uso e à transformação deste território. Dessa forma, compreende-se por que as limitações ao acesso à terra estão completamente ligadas às limitações ao uso do território.

Ainda de acordo com matéria feita pelo G1 (2014), outra característica presente na moradia de muitos desses haitianos, ao se fixarem em Andradas, é a moradia conjunta com outros haitianos. Como mostrou a reportagem, alguns moram em casas com sete colegas para que possam ajudar nas despesas de moradia e conseguir, assim, enviar dinheiro para suas famílias no Haiti.

Dessa forma, é possível compreender que, concentrados que estão na área urbana do município, os haitianos estão submetidos às condições de moradia inerentes a esse espaço. Esta discussão é relevante para tema em questão porque permite interpretar a maneira como a localidade geográfica também é de extrema importância para a construção e a transformação do território.

Desse modo, acredita-se que os imigrantes haitianos que se encontram no perímetro urbano transformam o território de Andradas através dos recursos que 
ali estão presentes. A moradia se faz essencial, pois é a partir dela que eles passam a se relacionar com outros objetos, bairros, pontos comerciais, escolas, dentre outros elementos do município que são importantes para seu funcionamento.

Por exemplo, conforme os migrantes se instalam em certos bairros, eles podem abrir comércios próximos de suas moradias ou escolher escolas que sejam mais próximas de suas casas para que seus filhos e filhas possam estudar com maior comodidade e segurança.

Ademais, isso faz com que novos locais sejam formados no território, como praças e parques, entre outros. Sendo assim, o território é modificado pela maneira com que esses indivíduos utilizam suas moradias e os equipamentos públicos. É também interessante ressaltar que, devido à moradia conjunta desses haitianos, as experiências de vida no novo país são também diferentes.

Como afirma Santos (2000), existe uma relação dialética de mudança entre o ser humano e o espaço. Sendo assim, o haitiano muda o espaço em sua volta, assim como o espaço condiciona sua dinâmica cotidiana. Um exemplo dessa relação é a Igreja Pentecostal de Milagres do Haiti, fundada em 2015 pelo pastor Jefferson Verones (SECRETARIA MUNICIPAL DE ANDRADAS, 2020). Essa instituição religiosa, ao ser criada, altera, de alguma forma, a dinâmica do bairro e da rua. Já o local foi escolhido pelos haitianos ${ }^{3}$ para a criação da igreja por conta de suas características geográficas, como localização e acesso mais adequado aos fiéis que residem na cidade. Na igreja, cujo pastor é haitiano, os cultos são realizados na língua oficial dos imigrantes (crioulo) e em francês (PORTAL DE ANDRADAS, 2015).

A importância da atividade religiosa na qualidade de vida do imigrante está ligada à necessidade de preservar sua cultura ao chegar no Brasil. A manutenção de tais atividades no estrangeiro é necessária para a sua saúde mental, pois questões como a do preconceito advindo da xenofobia podem trazer problemas

\footnotetext{
${ }^{3}$ A igreja de localiza na rua Milton Sebastião Barbosa, 222, na Vila Maganhoto
} 
psicológicos àqueles que a sofrem e a religião pode auxiliar a lidar com esses problemas.

Na questão do uso do território, as instituições como a Igreja Pentecostal, ou, como dito por Louis durante a conversa, as diferentes igrejas pentecostais que podem ser montadas pelos haitianos fazem com que eles se locomovam e frequentem locais onde realmente acontecem, entre eles e os demais habitantes do município, reuniões e relações que não ocorreriam caso elas não existissem.

\section{EDUCAÇÃO}

A última coleta de dados acerca da educação no município de Andradas (IBGE, 2010) mostra que havia dezessete escolas de ensino infantil, com 1.730 alunos matriculados, dezoito escolas de ensino fundamental com 4.283 alunos matriculados e cinco escolas de ensino médio com 1.220 alunos matriculados. Dessas escolas (estaduais, municipais e particulares), treze eram municipais, seis localizadas na área urbana e sete na área rural.

De acordo com a Secretaria de Educação do município, ao chegarem à cidade, os haitianos buscam se matricular principalmente na EJA (Educação de Jovens e Adultos). Os que mais procuravam se inserir nesse nível de ensino eram os primeiros imigrantes haitianos, em sua maioria pais de família. Após algum tempo chegaram também as suas famílias e consequentemente houve a matrícula de crianças.

A Secretaria de Educação afirma que ainda é baixo o número de haitianos que estudam na Rede Pública de Ensino, porém, os que frequentam as escolas são muito queridos pelos colegas e possuem uma ótima capacidade cognitiva, sendo que a principal dificuldade encontrada por eles é a aprendizagem da língua portuguesa.

A interação por meio da educação entre haitianos e haitianas e andradenses denota o uso do território feito por eles, principalmente na questão 
de desenvolver uma ligação dialética, ou seja, uma relação de troca com esse "novo território", sendo ela a própria capacidade de transformar o território em troca do desenvolvimento socioespacial dos imigrantes.

A afirmação feita pela Secretaria de Educação de Andradas referente à cognição dos haitianos retrata, na verdade, uma realidade vivida pelos imigrantes que entram no Brasil. A questão é que nunca se duvidou da capacidade cognitiva desses haitianos, mas ainda assim foi retratada pela Secretaria de Educação essa informação, não deixando claro se é advinda da questão da diferente língua ou de um preconceito estrutural.

A interpretação feita a partir dessa informação é que no município de Andradas ainda parece perdurar uma visão retrógrada de pessoas vindas de países que se encontram em dificuldade ou que estão em situações adversas, como guerras civis ou catástrofes naturais. Além de completamente errônea, essa visão mostra como os haitianos podem ser recebidos ou tratados pelos andradenses. Ou seja, podem ser tratados de maneira diferenciada e, de certa forma, preconceituosa.

Assim, cabe colocar em questão o apontamento feito por Bernardo e Barbosa (2017), segundo o qual o conhecimento da língua do país onde o imigrante irá se fixar facilita sua integração e inserção social, com conhecimento da cultura local.

Levando em consideração que a aquisição da língua traz consigo o conhecimento da cultura que ela representa, da maneira com que os falantes dessa língua enxergam as situações do cotidiano, do como fazer, como agir, como solucionar os problemas do dia a dia, essa proposta objetiva ir além da simples aceitação desses fatores socioculturais por parte do/as alunos/as. (BARBOSA; BERNARDO, p. 62, 2017).

Fica evidente também que, por meio da educação, o imigrante haitiano muda o território de Andradas. Quando se analisam casos como o apresentado 
pela Secretaria de Educação de Andradas, compreende-se que o interesse mostrado pelos imigrantes haitianos na educação é uma maneira de compreender como o território pode mudar em uma larga escala através desses indivíduos, pois o maior conhecimento da língua do país de destino possibilita o uso amplo e inclusivo do território.

Por meio da educação e do ensino superior é possível fazer mudanças territoriais em âmbitos diferentes. Em nosso entendimento, esse processo pode estar ocorrendo a partir do acesso à educação formal por esse grupo de imigrantes. Esse acesso certamente tem possibilitado mudanças territoriais em volta desses imigrantes.

A educação, portanto, é um processo-chave na inserção dos imigrantes haitianos no território andradense. Quanto mais inseridos nas dinâmicas municipais, mais habilitados estão a usar o território de maneira plena. Além disso, a especialização por meio da educação permite a expansão da cultura haitiana em diferentes setores do município, permitindo ainda mais o uso do território por esse grupo.

No entanto, quando se fala de alunos matriculados desde o ensino fundamental até a EJA, é necessário analisar se de fato o haitiano e a haitiana possuem acessibilidade a essas escolas. Assim, ao se falar da quantidade de alunos matriculados, é sempre necessário pensar no número total de imigrantes haitianos em Andradas, levando em conta as crianças, os adolescentes e aqueles que têm vontade de terminar seus estudos. Infelizmente, a falta de números exatos na Secretaria de Educação de Andradas faz com que seja cada vez mais difícil compreender como é a condição educacional desse grupo.

Também é preciso pensar naqueles que ainda estão por vir. Se as escolas têm dificuldade de integrar os haitianos que já estão no município, é necessário compreender que com o tempo o número de haitianos pode aumentar (já que muitos planejam trazer suas famílias). Um aspecto central a ser considerado pelo 
governo municipal e pelos gestores educacionais é que, como todos os andradenses, os imigrantes haitianos também têm o direito de estudar.

\section{SAÚDE}

O município de Andradas conta com a presença de sete Unidades Básicas de Saúde (UBSs) (Campestrinho, Gramínea, Barra, Óleo, Jardim Mantiqueira II, Jardim Rio Negro e Horto). A presença das UBSs ocorre tanto na região rural quanto na urbana, porém se dá majoritariamente em áreas urbanas e nos distritos (MINISTÉRIO DA SAÚDE, 2020).

De acordo com a Secretaria de Planejamento Urbano de Andradas (2020), existem UBSs nos dois distritos de Andradas (Campestrinho e Gramínea) e nos bairros do Óleo e da Barra, que se localizam nas áreas rurais. O município teve quatro ESFs (Estratégias Saúde da Família) descredenciadas devido ao não cumprimento do prazo para retorno de informações aos gestores municipais estabelecido pela Política Nacional de Atenção Básica. Isso indica uma possível falta de atenção ao atendimento dos andradenses e, consequentemente, dos imigrantes haitianos em Andradas. Como mostra a Tabela 2, as sete UBSs estão espalhadas ao longo do município com instalação em locais estratégicos.

A Figura 3 representa a localização dessas UBSs no município de Andradas. Como se pode observar, as UBSs estão geograficamente espalhadas pelo território de Andradas, mas se localizam sobretudo na sede do município e na porção sul e na extremidade oeste. 
Tabela 2: UBS's do município de Andradas (MG) e seus respectivos endereços, 2021

\begin{tabular}{ll}
\hline \multicolumn{1}{c}{ UBS } & \multicolumn{1}{c}{ Endereços } \\
\hline $\begin{array}{l}\text { UBS IRMA MARIA OLIMPIA DE } \\
\text { MAGALHAES NOGUEIRA }\end{array}$ & $\begin{array}{l}\text { R. Argemiro Pereira de Oliveira, } 194 \text { - } \\
\text { Horto }\end{array}$ \\
$\begin{array}{l}\text { UBS DR LEOPOLDO PIO DE } \\
\text { MAGALHAES }\end{array}$ & R. dos Ribeiros, S/N - Jardim Rio Negro \\
$\begin{array}{l}\text { UBS DOUTOR JOÃO BATISTA SALES } \\
\text { RIBEIRO }\end{array}$ & $\begin{array}{l}\text { R. Manoel Pereira Caldas de Mesquita, } \\
\text { S/N - Gramínea }\end{array}$ \\
$\begin{array}{l}\text { UBS VEREADOR MANOEL ADOLFO } \\
\text { MARQUES }\end{array}$ & $\begin{array}{l}\text { Praça Antônio Borges Santos, S/N - } \\
\text { Campestrinho }\end{array}$ \\
UBS ANTONIO DIAS DE PAUDA I & $\begin{array}{l}\text { R. Vereador Sebastião Dias, S/N - Oleo } \\
\text { UBS SENHORA MARIA CATARINA }\end{array}$ \\
$\begin{array}{l}\text { Avenida Francisco Pereira Caldas } \\
\text { DONATI RISSO }\end{array}$ & $\begin{array}{l}\text { Mesquita, S/N - Jardim Mantiqueira II } \\
\text { UBS DA BARRA }\end{array}$ \\
\hline
\end{tabular}

Fonte: Ministério da Saúde, 2021

Figura 3 - Localização das UBSs no município de Andradas (MG).

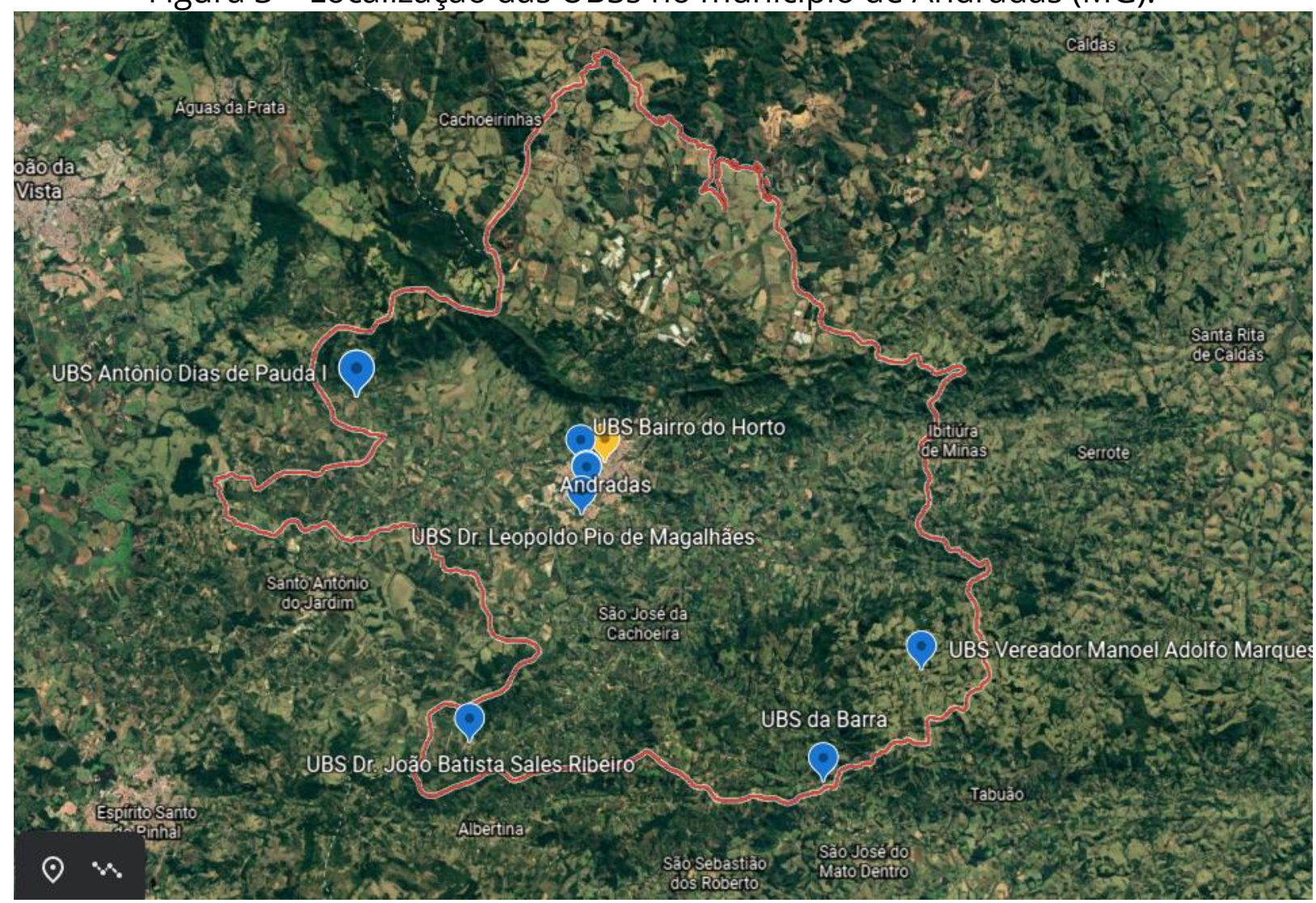

Fonte: Google Earth, 2010. 
De acordo com os dados oferecidos pelo IBGE (o último Censo feito em Andradas no quesito saúde é de 2010), o município possui cerca de vinte unidades do SUS (Sistema Único de Saúde), com treze SUS ambulatoriais, dois emergenciais e um de internação. $O$ total de unidades médicas no município é de 23 unidades, quinze delas públicas (todas municipais) e oito privadas.

Ante informação dada de que os haitianos estão na área urbana, entendese que eles têm acesso ao serviço de saúde, pois as sete unidades estão bem espalhadas ao longo do território municipal, como já apontado, fazendo com que o acesso também seja mais facilitado para habitantes de áreas um pouco mais afastadas do centro do município.

Os dados de saúde do município impõem uma reflexão sobre como Andradas utiliza os aparelhos médicos e os postos de saúde para atender às necessidades de sua população. Quando se discute a questão do haitiano em Andradas, é importante atentar em que a necessidade de alcançar os aparelhos de saúde é de extrema importância.

$\mathrm{Na}$ questão da saúde mental desses haitianos, destaca-se que a necessidade do trabalho, juntamente com a vontade de garantir segurança financeira para suas famílias, acaba causando um impacto na questão do lazer desses imigrantes. Um exemplo é o dado pela entrevista do G1 (2014), na qual o haitiano Emmanuel disse que se priva de seu esporte favorito, o futebol, para evitar que se machuque e não consiga trabalhar.

Essas questões trazem mudanças quando se discute a maneira como os haitianos e haitianas modificam o território em Andradas. Por mais que a saúde possa ser acessível, questões como a trabalhista também podem dificultar o seu acesso à saúde, como fica claro na reportagem. Se até mesmo num caso em que o haitiano se machuque ele tem certa preferência por não perder um dia de trabalho, isso impacta em outras questões, como, por exemplo, na realização de exames rotineiros (impacto causado pela possibilidade de demora para a cura ou 
mesmo pelo surgimento de outras patologias).

A mudança imposta ao território dependerá diretamente da forma como eles se arranjam dentro de seus limites, ou seja, pela prioridade dada a cada local por sua proximidade com hospitais e postos de saúde, entre outros. Quanto mais incluídos esses haitianos estiverem na saúde do município, maior será a sua transformação no território.

A inclusão na saúde se faz necessária para o uso do território, pois a saúde está diretamente atrelada às condições físicas de vida dos imigrantes haitianos. Quando consideramos os indivíduos como agentes que usam o território, a condição física torna-se um alicerce para que isso aconteça. Dessa forma, condições precárias de saúde não permitem que se possam inserir no trabalho ou em atividade de lazer, causando um reduzido uso do território. Assim, questões como a do saneamento estão diretamente ligadas à saúde e, consequentemente, ao uso do território.

Quanto ao saneamento básico, foi informado pela Secretaria de Planejamento Urbano de Andradas (2020) que o município possui, a partir dos novos empreendimentos feitos, tratamento de esgoto, porém a parte mais antiga da cidade não conta com tratamento de seus efluentes (de acordo com o dicionário elaborado pela Oxford Languages, efluentes são resíduos líquidos expelidos no decorrer de um processo industrial).

\section{CONSIDERAÇÕES FINAIS}

De acordo com o que foi levantado e analisado neste trabalho, o município de Andradas mantém boas relações com os haitianos que ali residem. Porém não se pode confundir boas relações com descaso, que é o que acontece na maioria das vezes. Não é porque esses imigrantes haitianos não sofrem um preconceito claro ou não são destratados publicamente que estão tendo suas necessidades atendidas pela prefeitura de Andradas. Cabe destacar que muitos andradenses 
sabem da presença haitiana no município, mas não sabem exatamente o que fazem, onde moram ou até mesmo quantas crianças haitianas ao todo estudam no município.

Como foi constatado ao desenvolver a pesquisa, é importante compreender que a inclusão desses haitianos na formação e no funcionamento de Andradas é de extrema importância para que eles possam ter uma qualidade de vida digna, mas também para que possam utilizar o território da maneira que lhes convém. Quanto maior for a limitação na inserção desses imigrantes haitianos, maior será a limitação do uso do território por eles.

Como foi dito por Louis Delhomme Desinord, 39 anos, hoje em dia a entrada dos haitianos está mais fácil, mesmo com a dificuldade para retirada de documentos como vistos e outros. Sendo assim, cabe compreender que por mais que se tenha uma boa quantidade de famílias haitianas em Andradas, esse número tende a aumentar conforme o passar dos anos devido ao fato de que as famílias que já residem no município de Andradas se estabilizam, trazendo assim o restante dos familiares (principalmente mãe, filhos e filhas). Ressalte-se que cabe à Prefeitura e aos órgãos públicos garantirem a qualidade de vida e o direito de uso do território para esses haitianos.

Portanto, é muito importante que as questões ligadas à qualidade de vida e ao uso do território sejam vistas por outras pessoas além dos próprios imigrantes haitianos. Por serem novos no país, muitas vezes eles não possuem perspectiva de que há exploração da mão de obra estrangeira, e devido a essa falta de perspectiva sobre a exploração e a exclusão a que podem estar sendo submetidos esta pesquisa se torna relevante para a vida desses imigrantes haitianos.

Pela falta de um conhecimento mais amplo dos andradenses sobre a presença haitiana no município e como a própria prefeitura não possui informações sobre eles é que se faz importante a conscientização desses 
imigrantes sobre as condições de vida e laborais a que são submetidos, para que reivindiquem seus direitos. Desse modo, é importante relatar como realmente é a vida desses grupos em seu novo país. Quanto mais se estudar sobre eles e seu uso do território, melhor se rá compreender sua qualidade de vida e o modo como usam o território em Andradas.

\section{REFERÊNCIAS BIBLIOGRÁFICAS}

BERNARDO, M. A. S.; BARBOSA, L. M. A. A Importância da Língua na Integração dos/as Haitianos/as no Brasil. Revista de Investigación sobre Migraciones, vol. 01, n.1, 2017.

BRAGA, J. L. R.; KAROL, E. A Temática dos Refugiados na Geografia da População. Anais... Seminário de Pós-Graduação em Geografia da UNESP de Rio Claro, 2009.

COGO, D.; SILVA, T. Entre a fuga e a invasão: alteridade e cidadania da imigração haitiana na mídia brasileira. Revista Famecos: Mídia, Cultura e Tecnologia, vol. 23, n. 1, 2016.

COGO, D.; PÁSSARO, M. A "foto roubada": mídias, visibilidade e cidadania da imigração haitiana no Brasil. Revista da Associação Nacional dos Programas de Pós-Graduação em Comunicação, E-compós, Brasília, vol. 20, n.1, 2017.

CNESNet (Secretaria de Atenção à Saúde). Dados sobre Leitos no município de Andradas. Disponível

em: <http://cnes2.datasus.gov.br/Mod_Ind_Tipo_Leito.asp?VEstado=31\&VMun=31026 0\&VComp $=202011>$. Acesso em 22 de dezembro de 2020.

G1. 'No Brasil eu me senti humano', diz haitiano que vive em Andradas, MG. Sul de Minas EPTV, disponível em: <http://g1.globo.com/mg/sul-deminas/noticia/2014/09/no-brasil-eu-me-senti-humano-diz-haitiano-que-vive-emandradas-mg.html>. Acesso em 21 de abril de 2021.

G1. Estabilidade financeira atrai haitianos a tentar recomeço em Andradas, MG. Sul de Minas EPTV, disponível em: <http://g1.globo.com/mg/sul-deminas/noticia/2014/05/estabilidade-financeira-atrai-haitianos-tentar-recomecoem-andradas-mg.html>. Acesso em 21 de abril de 2021.

G1. Terremoto no Haiti Matou 316 Mil, Afirma Premier. Disponível em:<http://g1.globo.com/mundo/noticia/2011/01/terremoto-no-haiti-matou-316- 
mil-afirma-premier.html>. Acesso em 21 de junho de 2021.

GOOGLE EARTH. Imagens de Satélite das UBS de Andradas. Disponível em: $<$ https://earth.google.com>. Acesso em 18 de novembro de 2020.

INFOSANBAS. Saneamento em Andradas (MG). Disponível em:<https://infosanbas.org.br/municipio/andradas-mg/>. Acesso em 25 de outubro de 2020.

IBGE. Tabela da relação de Negros e Brancos no Município de Andradas. Sistema IBGE de Recuperação Automática (SIDRA), disponível em: <https://sidra.ibge.gov.br/tabela/3175>. Acesso em 25 de Abril de 2021.

Mapa de Andradas (MG). Instituto Brasileiro de Geografia e Estatística, disponível em:< https://portaldemapas.ibge.gov.br/portal.php\#mapa11593>. Acesso em 21 de junho de 2021.

Dados de Saúde, Educação e Desenvolvimento do Município de Andradas.

Disponível

em: $<$ https://cidades.ibge.gov.br/brasil/mg/andradas/pesquisa/23/25124?detalhes=tr ue>. Acesso em 08 de janeiro de 2021.

Dados de Saúde, Educação e Desenvolvimento do Município de São Paulo.

Disponível

em:

$<$ https://cidades.ibge.gov.br/brasil/mg/andradas/pesquisa/23/25124?detalhes=tr ue>. Acesso em 06 de Dezembro de 2021.

LIMA, D. R. D. Informações sobre Planejamento Urbano de Andradas. Mensagem recebida por <gestao.secretaria@andradas.mg.gov.br> em 29 de dezembro de 2020.

LIMA, E. Informações sobre Educação de Andradas. Mensagem recebida por <educacao.erika@andradas.mg.gov.br> em 22 de dezembro de 2020.

MACEDO, C. A. Imigrantes Haitianos no Brasil: Trajetórias e Perspectivas. São Paulo: Editora Dialética, 2020.

MINAS GERAIS. Divisão de MG por Regiões de Planejamento. Portal do Governo de Minas Gerais, disponível em: <https://www.mg.gov.br/conteudo/conhecaminas/geografia/regioes-de-planejamento>. Acesso em 21 de junho de 2021.

MINISTÉRIO DA SAÚDE. Descredencia Equipes de Saúde da Família (ESF) por não cumprimento de prazo estabelecido na Política Nacional de Atenção Básica. Gabinete do Ministro, Portaria n 1.717, 2018. 
. Estabelecimentos de Saúde de Andradas. CSESNet, Secretaria de Atenção à Saúde, disponível em: <http://cnes2.datasus.gov.br/Exibe_Ficha_Estabelecimento.asp?VCo_Unidade=31 02602212579\&VListar=1\&VEstado=31\&VMun=310260>. Acesso em 5 de janeiro de 2021.

. Cadastro Nacional de Estabelecimentos de Saúde. CSESNet, Secretaria de Atenção à Saúde, disponível em: $<$ http://cnes2.datasus.gov.br/Mod_Ind_Unidade_Listar.asp?VTipo=02\&VListar=1\& VEstado $=31 \& V M u n=310260 \& V S u b U n i=\& V C o m p=201603>$. Acesso em 5 de janeiro de 2021.

MOREIRA, V. E.; HESPANHOL, R. A. M. O Lugar como uma Construção Social. Revista Formação, n. 14 vol. 2, pp. 48-60, 2007.

NETTO, J. P. Introdução ao Estudo do Método de Marx. São Paulo: Expressão Popular, 2011.

PACHI, P. A Migração Haitiana e as Mudanças na Cidade de São Paulo. Idéias, Campinas, vol. 11, pp. 1-29, 2020.

PORTO, G. C. S. Evolução da rede de localidades centrais na Bahia nos séculos XIX e XX: Permanências, Complexidades e Amadurecimento. Tese (doutorado em Geografia). Universidade Federal de Minas Gerais, Belo Horizonte, 2014. Disponível em: https://repositorio.ufmg.br/bitstream/1843/IGCC9NBQ9P/1/tese_gil_carlos_silveri a_porto.pdf >. Acesso em: 17 de jul. 2021.

. Patrimonialização, território usado e processo de registro da feira livre de domingo de Alfenas (MG) como bem cultural imaterial do município. Caderno de Geografia, vol. 31, Número Especial 2, 2021. Disponível em: < http://periodicos.pucminas.br/index.php/geografia/article/view/27036 >. Acesso em: 15 de out. 2021.

A constituição de lugares por imigrantes internacionais e refugiados no período atual: uma leitura geográfica crítica em construção. In: SILVA, M. A.; PORTO, G. C. S. Revisitando um pensamento revolucionário: 20 Anos sem Milton Santos. Salvador: Edufba, 2021 (no prelo).

PREFEITURA MUNICIPAL DE ANDRADAS. Dados Demográficos. Disponível em: $<$ http://www.andradas.mg.gov.br/dados-demograficos>. Acesso em 06 de janeiro de 2021. 
Planejamento Urbano. Disponível em: <http://www.andradas.mg.gov.br/planejamento-urbano>. Acesso em 06 de janeiro de 2021.

. Pastor abre igreja para haitianos que moram e trabalham em Andradas, MG. Disponível em: $<$ https://andradas.portaldacidade.com/noticias/educacao/pastor-abre-igrejapara-haitianos-que-moram-e-trabalham-em-andradas-mg>. Acesso em 26 de outubro de 2020.

Plano Municipal de Saneamento Básico. Disponível em:<http://www.andradas.mg.gov.br/downloadsOficiais/3501leiordinaria1836de8dezembrode2017.pdf>. Acesso em 26 de outubro de 2020.

Readequação do Plano Municipal de Saneamento Básico de Andradas para a Projeção de Prognóstico e Plano de Execução até 2055. Projeto Andradas com Você é Mais, Andradas, 2018.

SANTOS, M. Metamorfoses do espaço habitado: Fundamentos Teórico e Metodológico da Geografia. São Paulo: Hucitec, 1988.

O Território e o Saber Local: Algumas Categorias de Análise. Cadernos IPPUR, Rio de Janeiro, Ano XIII, n. 2, 1999.

Por uma outra Globalização. Rio de Janeiro: Editora Record, 2000.

SANTOS, M; SILVEIRA, M. L. O Brasil: território e sociedade no início do século XXI. Rio de Janeiro: Record, 2001.

SECRETARIA MUNICIPAL DE SAÚDE. A Secretaria. Disponível em: <http://www.andradas.mg.gov.br/secretaria-municipal-de-saude-e-acao-social>. Acesso em 25 de outubro de 2020.

SILVA, G; CORSINI, L. A Diáspora Haitiana, Territorialidades e Conflitos. XIII ENANPEGE, São Paulo, 2019.

SOUZA, M. A. A Palavra e o Conceito 1. Canal no Youtube, disponível em: $<$ https://www.youtube.com/watch?v=tCUGyyfrxa0>. Acesso em 16 de março de 2021.

- A Palavra e o Conceito 2. Canal no Youtube, disponível em: $<$ https://www.youtube.com/watch?v=610skdDT0OA>. Acesso em 16 de março de 2021. 
A Palavra e o Conceito 3. Canal no Youtube, disponível em: $<$ https://www.youtube.com/watch?v=JsZiMsrFCtY>. Acesso em 16 de março de 2021.

Território Brasileiro: Usos e Abusos. Edições Territorial, Campinas, p. 11 26, 2003.

UNIFAL. II Colóquio sobre Migrações e Espaço Geográfico. Programa de Pósgraduação em Geografia UNIFAL-MG, disponível em: <https://www.youtube.com/watch?v=H8cQI-SrsbU>. Acesso em 22 de janeiro de 2021. 